\title{
Evaluasi Postur Kerja Operator Pemasangan Fire Brick Berbasis Metode Rapid Upper Limb Assessment dan Work Ergonomic Risk Assessment Di PT ABA
}

\author{
Muhammad Shofiyyullah $^{1 *}$, Nina Aini Mahbubah ${ }^{2 *}$ \\ ${ }^{1,2}$ Program Studi Teknik Industri, Fakultas Teknik, \\ Universitas Muhammadiyah Gresik \\ Jl. Sumatera 101 GKB Gresik - Indonesia 61121 \\ *Koresponden email: n.mahbubah@umg.ac.id, mshofiyyullah7@gmail.com
}

Diterima: 2 Oktober 2021

Disetujui: 3 November 2021

\begin{abstract}
A service provider is known as a job that profoundly depends on human work. Musculoskeletal disorder is considered a risk in such work. PT. ABA is a contractor service company that provide some services. The fire brick installation is a part of the refractory project, which is carried out continuously at the customer's request. Early results using the Nordic Body Map questionnaire found severe risk, which may lead to wellbeing difficulty. This study aims to evaluate musculoskeletal disorder risk due to inappropriate posture in fire brick installation activities. Rapid Upper Limb Assessment and Work Ergonomic Risk Assessment are ergonomic risk approaches used in this study. This research found two final scores using RULA and WERA calculation. RULA final score is 44 , classified as a medium score. The evaluation results of the RULA method obtained a final score of 7 with an extreme condition. An urgent improvement is a necessity in order to improve posture and work positioning of fire brick installation.
\end{abstract}

Keywords: ergonomy, NBM, WERA, RULA, risk, musculuskeletal

\begin{abstract}
Abstrak
Usaha jasa kontraktor merupakan suatu pekerjaan yang mayoritas penyelesaian pekerjaan menggunakan tenaga kerja manusia. Keluhan muskuskeletal merupakan risiko yang sering terjadi pada suatu pekerjaan yang dilakukan secara manual. PT. ABA merupakan suatu perusahaan jasa kontraktor dan Refractory merupakan salah satu jasa yang ditawarkan. Instalasi fire brick merupakan proyek bagian refractory yang dilakukan secara kontinyu atas permintaan pelanggan. Hasil identifikasi Nordic Body Map diketahui diketahui keluhan bagian tubuh dalam kategori sakit dan sangat sakit sehingga diperlukan analisis lebih lanjut. Penelitian ini bertujuan untuk mengevaluasi risiko otot muskuluskeletal akibat kesalahan postur tubuh aktivitas instalasi fire brick. Rapid Upper Limb Assesment dan Work Ergonomic Risk Assesment merupakan pendekatan risiko ergonomi yang digunakan dalam penelitian. Evaluasi aktivitas pemasangan fire brick dengan metode WERA diketahui bahwa nilai akhir 44 diklasifikasikan sebagai skor medium. Hasil evaluasi metode RULA diperoleh skor akhir 7 dengan tingkat risiko tinggi, sehingga dibutuhkan segera untuk perbaikan postur tubuh pada stasiun kerja pemasangan fire brick.
\end{abstract}

Kata Kunci: ergonomi, NBM, WERA, RULA., risiko, postur

\section{Pendahuluan}

Manual Material Handling (MMH) adalah aktivitas pemindahan bahan baku atau bahan antara secara manual di perusahaan manufaktur maupun jasa. Pemindahan material dari satu lokasi ke lokasi secara tradisional tersebut tidak dapat dielakkan meskipun pada industri yang menggunakan mesin atau peralatan otomasi canggih. Usaha jasa bidang kontraktor merupakan salah satu contoh bisnis yang menggunakan tenaga kerja manusia sebagai sumber daya utama dalam menyelesaikan proyek jasa tersebut. PT ABA merupakan suatu perusahaan yang bergerak di bidang jasa kontraktor. Perusahaan berdiri pada tahun 2015 berbentuk CV dan berubah menjadi PT pada tahun 2018 perusahaan ini berubah menjadi PT sampai sekarang. Salah satu bidang pekerjaan jasa PT. ABA yaitu refractory, suatu aktivitas pekerjaan jasa di perusahaan manufaktur yang menggunakan kiln, burner, atau bullnose.

Pekerjaan yang berhubungan dengan jasa refractory bertujuan untuk menjaga suhu bejana, pipa panas, dan boiler tetap stabil. Instalasi Fire Brick merupakan salah satu proyek kontinu yang dikerjakan perusahaan tersebut. Proses pemasangan fire brick ini dilakukan di dalam kiln yang memiliki diameter 6 meter. Terdapat 6 tahapan pemasangan fire brick yaitu proses pembongkaran, proses pemindahan batu fire 
brick, proses pembuatan mortar, proses pemasangan batu fire brick, dan proses finishing. Peta Proses Operasi pemasangan fire brick dalam mesin kiln dapat dilihat pada Gambar 1.

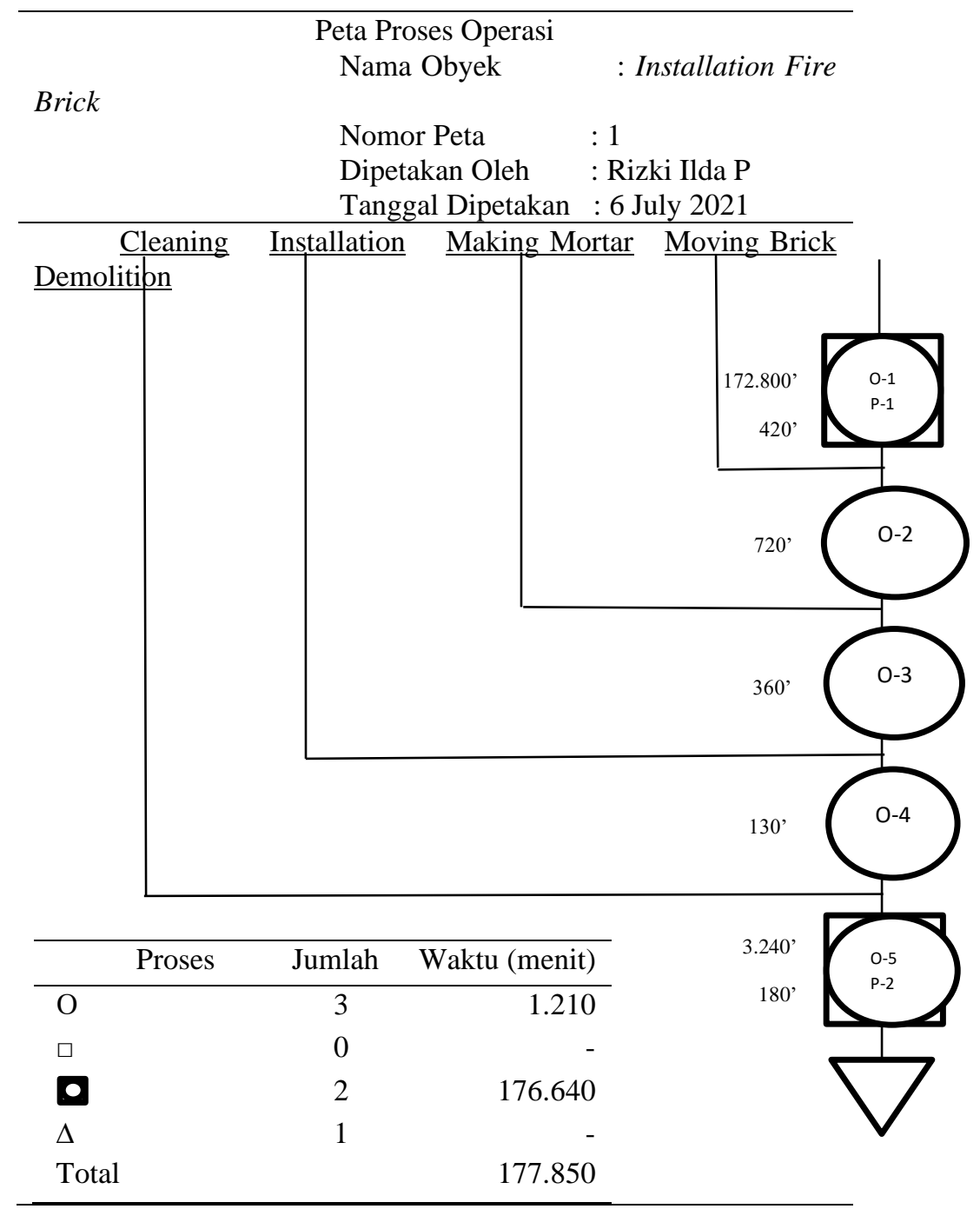

Gambar 1. Peta proses operasi instalasi Fire Brick Sumber: PT ABA, Pengolahan data

Gambar 1 merupakan peta proses operasi instalasi fire brick. Proses pembongkaran batu api (brick) ini memerlukan waktu 2 hari. Setelah selesai pembongkaran kemudian dilakukan cleaning pada area kiln agar pada saat pemasangan batu api dapat dilakukan dengan baik dan maksimal. Proses pemindahan batu fire brick dilakukan pemindahan batu api ke dalam mesin kiln dengan menggunakan forklift agar memudahkan pekerjanya untuk melakukan pemasangan di area kiln. Proses pembuatan mortar dilakukan pada saat akan memasang batu fire brick karena semen mortar merupakan zat yang mudah kering maka tidak bisa bertahan lama agar mortar tetap bisa digunakan. Proses pemasangan batu fire brick dilakukan di dalam area kiln dengan menggunakan mortar sebagai perekat agar menempel dengan kuat. Proses finishing dilakukan cleaning pada bagian yang telah dilakukan pengerjaan proyek di area kiln. Aktivitas MMH menyebabkan pekerja cepat merasakan kelelahan dan akan menimbulkan cedera jika dilakukan secara terus menerus. Akibat dari rasa sakit maupun cedera pada saat bekerja merupakan tanda adanya kesalahan pada kesehatan dan keselamatan kerja pada lokasi proyek yang akan mengganggu produktivitas. Hal tersebut berdampak risiko kecelakaan kerja dan penyakit jika tidak memperhatikan keamanan dan posisi ergonomis [1]. Pekerjaan yang dilakukan dengan gerakan secara berulang dapat menimbulkan gangguan kesehatan pada operator [2]. 
Berdasarkan walk through survey pada proses instalasi fire brick diketahui bahwa mayoritas proses pekerjaan dilakukan secara manual. Hasil wawancara awal dengan operator pemasangan fire brick diketahui bahwa pekerja merasakan kelelahan yang berlebih sebagai dampak dari aktivitas pekerjaan. Kesalahan postur kerja berdasarkan tinjauan ilmu ergonomi akan mengakibatkan permasalahan kelainan pada otot musculoskeletal bagi pekerja [3]. Nordic Body Map (NBM) merupakan suatu alat berbentuk kuesioner yang dapat digunakan untuk mengukur keluhan sakit pada bagian tubuh pekerja yang biasa disebut dengan musculoskeletal disorder. Kuesioner NBM dapat digunakan sebagai deteksi tingkat keluhan pada otot yang diderita pekerja [4]. Hasil penyebaran kuesioner NBM pada operator pemasangan fire brick di visualisasikan Gambar 2.
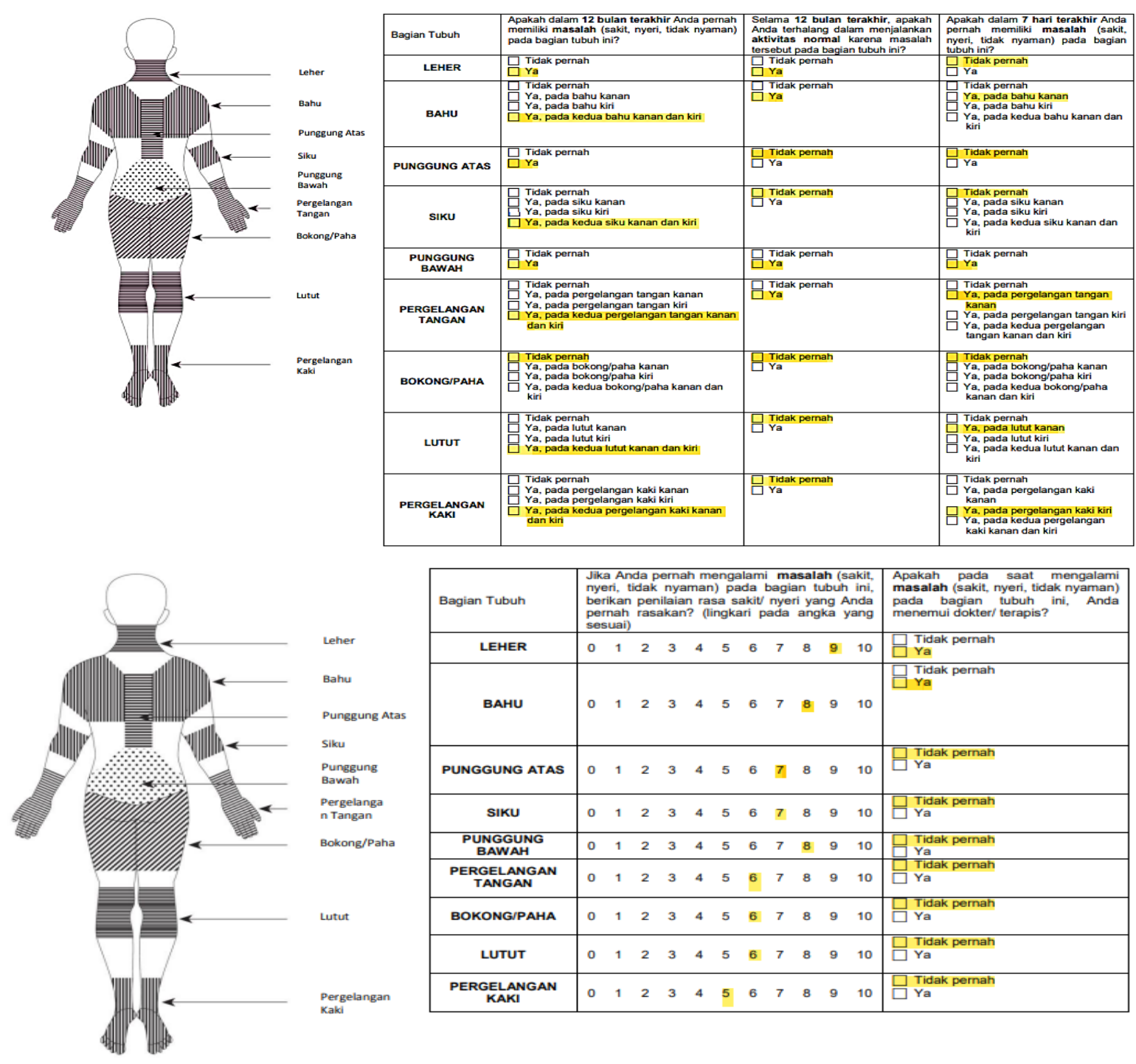

Gambar 2. Hasil kuesioner nordic body map Sumber: Pengolahan data [7]

Hasil pengisian kuesioner NBM pada operator fire brick pada Gambar 2 memperlihatkan bahwa operator mengalami gangguan dan keluhan pada pergelangan kaki, pergelangan tangan, punggung atas. Gangguan dan keluhan operator juga terjadi pada punggung bawah, lutut, siku, bahu dan leher. Hasil NBM mengidentifikasi tingkat keluhan peringkat tinggi sehingga risiko cedera atau sakit semakin besar. Kesalahan postur dalam melakukan aktivitas pekerjaan berdampak pada hasil pekerjaan karena tidak dilaksanakan secara maksimal [5]. Pada dasarnya bekerja menggunakan perangkat yang ada pada tubuh dan hampir seluruh anggota tubuh digunakan pada saat bekerja [5]. Kondisi kelelahan karyawan akan berdampak pada kinerja operator sehingga target pekerjaan yang ditetapkan tidak akan terpenuhi [6]. Keluhan kelainan otot muskuluskeletal dapat diklasifikasikan menjadi 2, yaitu pertama keluhan sementara yang dialami pada saat otot merasakan beban statis dan dapat dihentikan jika beban statis dihentikan segera 
[6]. Kedua terdapat keluhan tetap yang dialami pada saat merasa letih dan bersifat menetap, akan berhenti jika pekerjaan tersebut dihentikan [6]. Secara umum, aplikasi risiko ergonomi pada industri jasa atau manufaktur tidak termasuk dalam agenda pengelolaan risiko perusahaan [7]. Pada umumnya definisi ergonomi membahas tentang masalah yang berhubungan antara manusia yang bekerja dengan situasi tertentu serta menentukan postur kerja dari objek yang digunakannya [8]. Ergonomi dapat diaplikasikan pada saat melakukan aktivitas maupun beristirahat dengan batasan dan kemampuan manusia dari segi mental maupun fisik agar dapat melakukan pekerjaan dengan efektif [9]. Pada kondisi operator pada bagian pemasangan memiliki risiko cukup besar selain itu fasilitas kerja juga kurang ergonomis sehingga menyebabkan keluhan pada pekerja [10].

NBM memiliki kelemahan yaitu subyektivitas partisipannya cukup tinggi sehingga memerlukan pendekatan risk ergonomic yang lebih obyektif untuk menentukan risiko musculoskeletal disorder pada pekerja [11]. Aktivitas pemasangan fire brick memerlukan durasi waktu lebih dari 8 jam per hari dan berada pada lubang dengan diameter 6 meter mengakibatkan efek risiko ergonomi sesuai hasil NBM sehingga diperlukan evaluasi lebih lanjut. Dalam penyelesaian untuk mencari kuesioner NBM pada operator cukup memerlukan waktu hanya 2 hari sehingga cukup cepat penyelesaiannya dan responden tidak merasa terganggu juga telah menyetujui dalam pengambilan data tersebut.

Penelitian ini bertujuan untuk mengevaluasi postur tubuh operator pemasangan fire brick dengan menggunakan metode Work Ergnonomy Risk Assesment (WERA) dan Rapid Upper Limb Assessment (RULA). Jika dalam penerapan ergonomi tidak dapat dilakukan dengan baik maka menimbulkan rasa tidak nyaman dan keluhan pada tubuh tertentu [12]. Metode RULA berfungsi untuk menilai postur tubuh pada anggota tubuh bagian atas dan dikembangkan dalam bidang ergonomi untuk mengidentifikasi kelainan yang akan dialami oleh pekerja saat melakukan pekerjaan dan dengan cara melakukan evaluasi bagian upper limb [13]. WERA digunakan sebagai alat observasi guna melakukan mengidentifikasi suatu gerakan serta posisi aktifitas pekerjaan berpotensi musculoskeletal dissorder pada operator yang bekerja [14].

\section{Metode Penelitian}

Obyek penelitian adalah proyek aktivitas pemasangan fire brick pada mesin kiln. Responden penelitian yaitu 6 dari 10 pekerja yang sedang melakukan pemasangan fire brick yang berada di dalam mesin kiln. Pemilihan 6 responden berdasarkan hasil keluhan pada kuesioner NBM pada aktivitas pemasangan fire brick memerlukan analisis lebih lanjut. Observasi lapangan dilakukan selama 6 bulan pada Januari - Juli 2021. Desain kuesioner NBM, worksheet metode RULA dan WERA merupakan instrumen yang digunakan dalam penelitian. Tahap selanjutnya dilakukan perhitungan metode RULA dan WERA untuk membandingkan seberapa besar pengaruh terhadap operator pemasangan fire brick dengan cara menghitung posisi kerja pada tubuh operator sebagaimana hasil yang didapatkan jika memperoleh nilai yang tinggi diperlukan segera perbaikan posisi postur kerja pada operator tersebut.

\section{Tahapan Metode Rappid Upper Limb Assessment}

Dalam pengukuran dimulai dari mengidentifikasi dan mengamati bagian postur tubuh operator selama bekerja pada stasiun kerja yang dilakukan. Dengan dapat mengetahui sudut dan beban pekerja pengukuran dapat dilakukan dengan cukup mudah dan cepat karena pengukuran hanya dilakukan pada bagian atas tubuh saja. Untuk menerapkan metode RULA dapat dilihat pada Gambar 3. Serta telah dilakukan standarisasi dan dijadikan ketentuan perhitungan metode RULA [15]. Perhitungan RULA diklasifikasikan dalam 13 tahapan sebagai berikut [15]:

1. Tuliskan penilaian bagian Upper Arm Score, selanjutnya penambahan nilai berikut:

a. Jika bahu digerakkan ke atas : +1

b. Jika posisi upper arm menjauhi tubuh $:+1$

c. Jika lengan operator tertopang atau bersandar : -1 


\section{RULA Employee Assessment Worksheet}

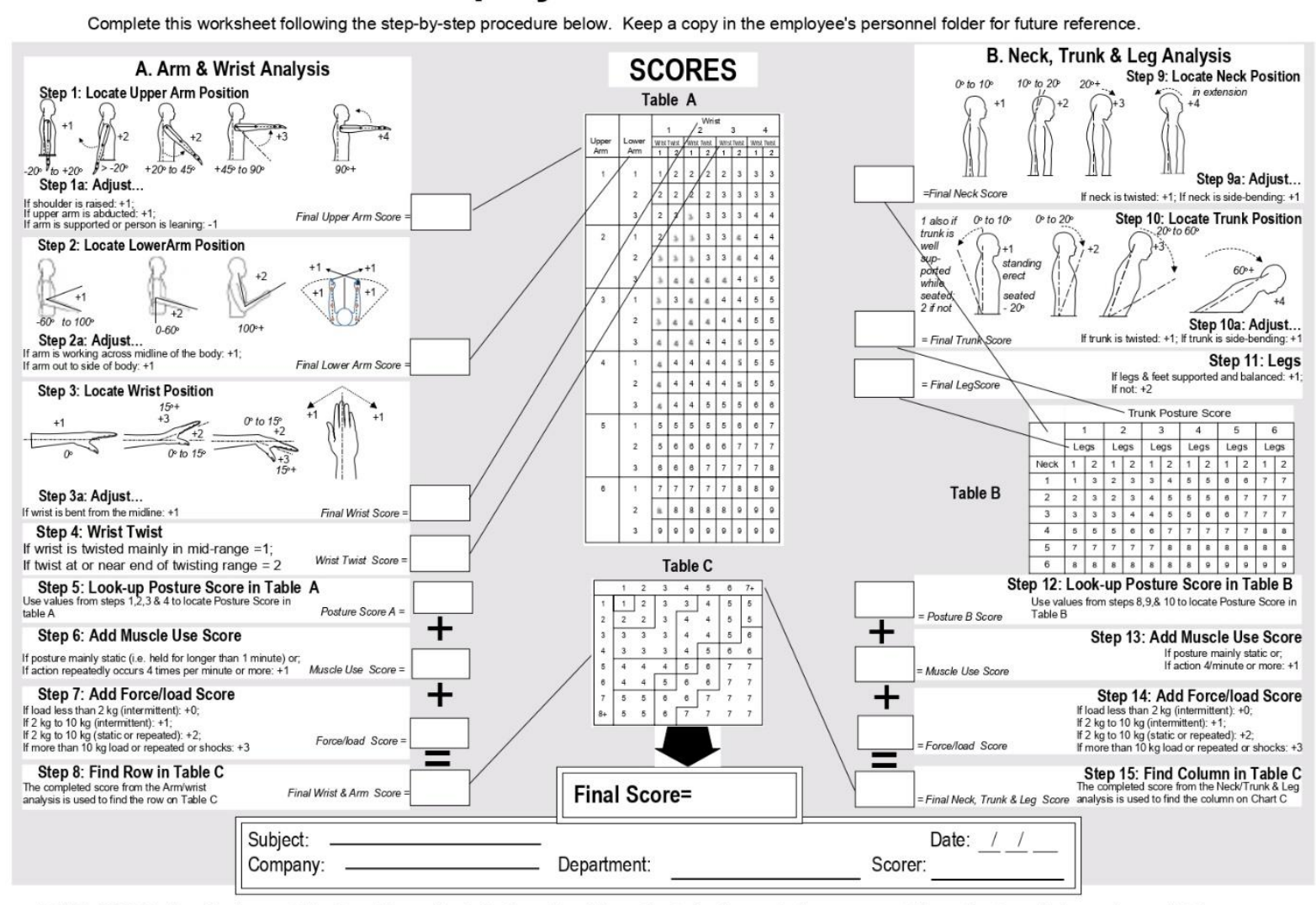

FINAL SCORE: 1 or $\mathbf{2}$ = Acceptable; 3 or $\mathbf{4}$ investigate further; 5 or $\mathbf{6}$ investigate further and change soon; 7 investigate and change immediately Source: MCAtamney, L. \& Corlett, E.N. (1993) RULA: a survey method for the imvestigation of work-related upper limb disorders, Applied Ergonomics, 24(2) 91-99. (- Professor Alan Hedge, Comell University, Feb. 2001

Gambar 3. Workheet RULA Sumber: Ref. [15]

2. Tuliskan penilaian pada Lower Arm Position, apabila salah satu tangan bergerak hingga melintasi garis tengah atau meliwati sisi tubuh beri skor +1 .

3. Beri skor untuk bagian pergelangan tangan (wrist position), apabila pergelangan tangan bengkok ke samping melebihi batas garis tengah beri tambahan skor +1

4. Beri skor tambahan +1 apabila pergelangan tangan terpelintir hingga batas tengah, dan +2 apabila pergelangan tangan terpelintir mendekati batas akhir.

5. Menggunakan langkah 1 sampai 4 untuk kalkulasi Gambar 3 poin A.

6. Beri tambahan nilai +1 jika penggunaan otot (muscle use) apabila didominasi postur statis atau aktivitas dilakukan 4x per menit.

7. Tambahan nilai untuk beban yang disesuaikan sesuai persyaratan berikut:
a. Jika beban $<2 \mathrm{~kg}$. (berselang) $:+0$
b. Jika beban 2 hingga 10kg. (berselang) : 1+
c. Apabila muatan 2 hingga $20 \mathrm{~kg}$. (statis atau berulang) : $2+$
d. Apabila muatan lebih dari $10 \mathrm{~kg}$. atau berulang atau terguncang $:+3$

8. Gunakan skor dari langkah 5-7 untuk menghitung skor wrist/arm.

9. Tuliskan penilaian pada posisi leher, selanjutnya mengikuti persyaratan berikut:
a. Jika leher terkilir diberikan +1
b. Jika leher miring ke samping diberikan +1

10. Tuliskan nilai pada posisi tubuh, selanjutnya mengikuti persyaratan berikut:
a. Jika tubuh terkilir diberikan +1
b. Jika tubuh miring ke samping diberikan +1

11. Tuliskan nilai pada posisi kaki tegak/ tertopang dengan nilai +1 , jika tidak beri nilai +2 .

12. Gunakan skor cara ke 9 sampai 11 dan dengan urutan yang sama kalkulasikan nilai pada Gambar 3 Poin B.

13. Tambahkan nilai +1 pada penggunaan otot (muscle use) apabila didominasi postur statis atau aktivitas dilakukan $4 \mathrm{x}$ per menit. 


\section{Tahapan Metode Workplace Ergonomy Risk Assesment}

WERA digunakan sebagai alat observasi guna melakukan mengidentifikasi suatu gerakan serta posisi postur kerja berpotensi kelainan musculoskeletal pada operator yang bekerja pada suatu stasiun kerja tertentu [14]. Dalam penilaian WERA dimulai dengan skoring sistem pada setiap faktor risiko pekerja dan memasukkan hasil perhitungan. WERA dengan memberi tanda pada persimpangan kolom dan baris [14]. Menentukan serta menghitung jumlah skor akhir disetiap bagian penilaian faktor yang sudah terisi dan menentukan kategori level dari jumlah skor yang diperoleh pada tiap bagian faktor risiko dari tingkatan low, medium, sampai high. Gambar 4 merupakan tahapan worksheet perhitungan metode WERA sebagai berikut [14].

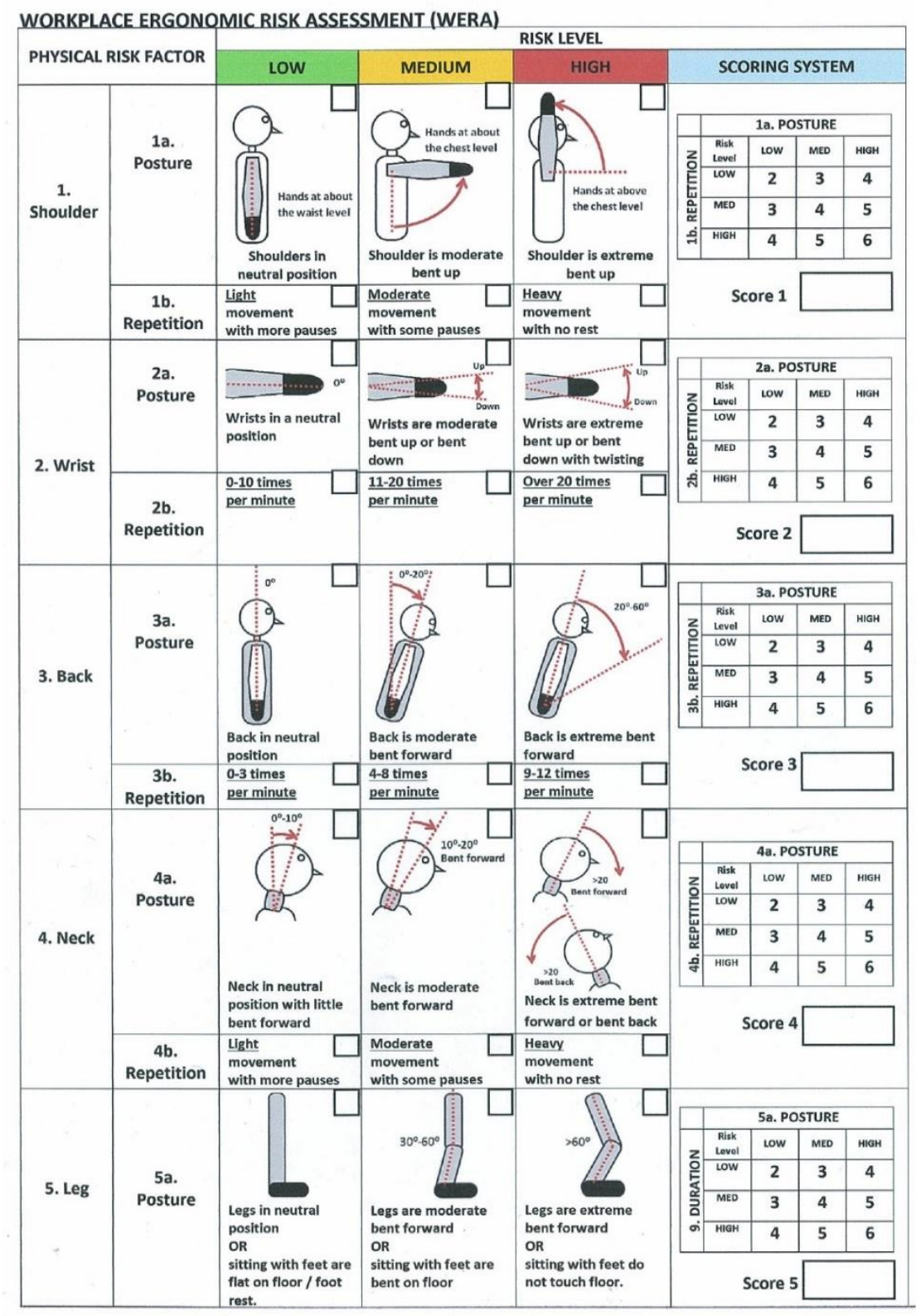

๑๑ 2011 Universiti Teknologi Malaysia - All rights reserved. 


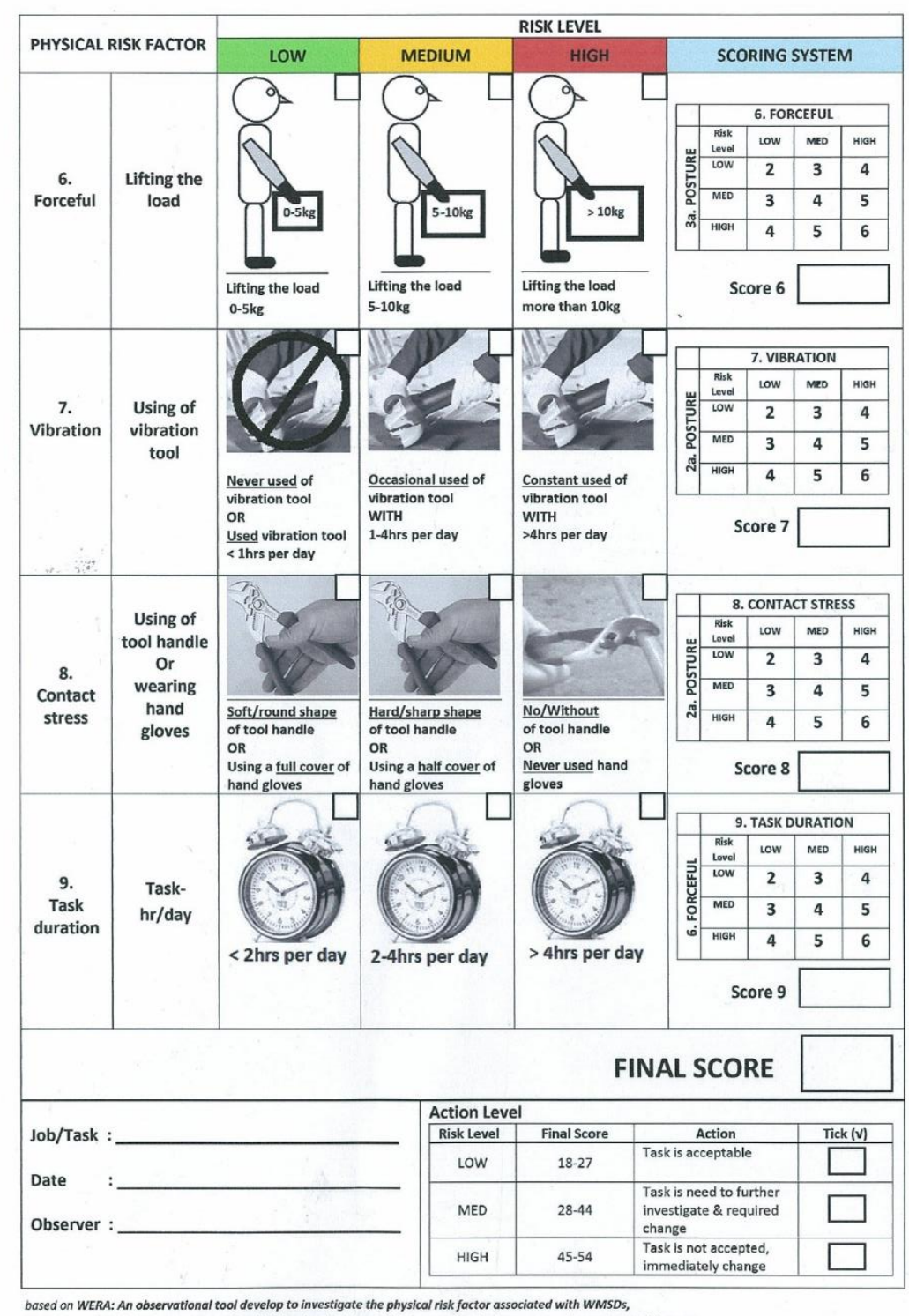

based on WERA: An observational tool develop to investigate the physical risk factor associated with WMSDs

Gambar 4. Worksheet WERA

Sumber: Ref. [16]

\section{Hasil Dan Pembahasan}

Hasil pengisian kuesioner NBM pada Gambar 2 menunjukkan bahwa pada aktivitas pemasangan, pengambilan dan pengangkatan fire brick merupakan kegiatan pekerjaan instalasi fire brick yang memerlukan evaluasi lebih lanjut menggunakan pendekatan RULA dan WERA. Hasil evaluasi postur kerja dimulai dengan perhitungan postur tubuh aktivitas pemasangan, pengambilan dan pengangkatan fire brick menggunakan pendekatan WERA dan dilanjutkan dengan evaluasi postur tubuh dengan pendekatan RULA. Perbandingan evaluasi di stasiun kerja pemasangan, pengambilan dan pengangkatan fire brick dibahas pada bagian akhir.

\section{Evalusi WERA Pada Postur Operator Stasiun Kerja Pemasangan Fire Brick}

Pada aktivitas stasiun kerja pemasangan, pengambilan, dan pengangkatan fire brick dilakukan di dalam kiln dapat dilihat pada Gambar 5. 

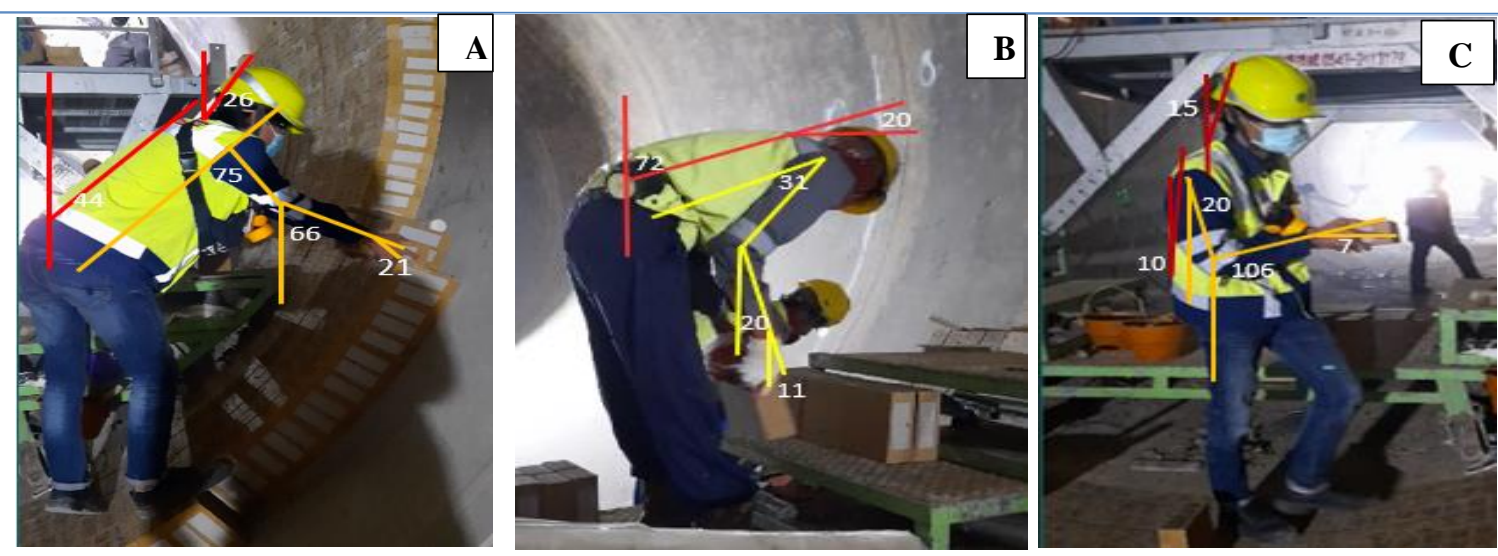

Gambar 5. Postur Tubuh Aktivitas Pemasangan (A), Pengambilan (B), Pengangkatan (C) Fire Brick Sumber: PT ABA, Pengolahan data

Pada Gambar 5 menunjukkan bahwa Gambar 5 A proses berlangsungnya pemasangan fire brick, Gambar 5 B ialah proses pengambilan fire brick, dan Gambar C proses pengangkatan perpindahan sebelum menuju pemasangan fire brick. Dari ketiga tahapan tersebut merupakan proses pemasangan fire brick dengan diketahui sudut dari setiap titik bagian yang telah ditentukan untuk melakukan perhitungan metode WERA dan RULA. Diketahui dari posisi Gambar 5 A membentuk sudut lengan atas pekerja $75^{\circ}$. Pergelangan tangan membentuk sudut $21^{\circ}$. Posisi punggung operator membentuk sudut $44^{\circ}$. Posisi lengan bawah membentuk sudut $66^{\circ}$. Posisi sudut leher membentuk sudut $26^{\circ}$. Kemudian pada posisi kaki dalam kondisi normal dalam keadaan tegak tidak tertekuk. Untuk menentukan pengukuran dapat dilakukan terhadap pengukuran menggunakan metode WERA di Tabel 1.

Tabel 1. Evaluasi WERA tingkatan risiko di aktivitas pemasangan

\begin{tabular}{|c|c|c|c|}
\hline \multicolumn{2}{|c|}{ Faktor Risiko Fisik } & \multirow{2}{*}{$\begin{array}{c}\text { Uraian } \\
75^{\circ}\end{array}$} & \multirow{3}{*}{$\begin{array}{c}\text { Tingkat } \\
\text { Risiko } \\
\mathrm{M} \\
\mathrm{M}\end{array}$} \\
\hline 1. Bahu & 1a. Posisi badan & & \\
\hline & 1b. Repetisi & $\begin{array}{l}\text { Gerakan dengan } \\
\text { beberapa berhenti }\end{array}$ & \\
\hline \multirow[t]{2}{*}{ 2. Pergelangan Tangan } & 2a. Posisi badan & $\begin{array}{l}\text { Tangan memutar } \\
\text { dengan posisi } 21^{\circ}\end{array}$ & $\mathrm{H}$ \\
\hline & 2b. Repetisi & $\begin{array}{c}15 \text { gerakan dalam } 1 \\
\text { menit }\end{array}$ & M \\
\hline \multirow[t]{2}{*}{ 3. Punggung } & 3a. Posisi badan & $44^{\circ}$ & $\mathrm{H}$ \\
\hline & 3b. Repetisi & $\begin{array}{l}\text { Dalam } 1 \text { menit } \\
\text { terdapat } 3 \text { gerakan }\end{array}$ & $\mathrm{L}$ \\
\hline \multirow[t]{2}{*}{ 4. Leher } & 4a. Posisi badan & $26^{\circ}$ & $\mathrm{H}$ \\
\hline & 4b. Repetisi & $\begin{array}{l}\text { Gerakan dengan } \\
\text { beberapa berhenti }\end{array}$ & M \\
\hline \multirow[t]{2}{*}{ 5. Kaki } & 5a. Posisi badan & $\begin{array}{c}\text { Posisi kaki tegak } \\
\text { lurus }\end{array}$ & $\mathrm{L}$ \\
\hline & 9. Waktu kerja & Melebihi 4 jam & $\mathrm{H}$ \\
\hline \multirow[t]{2}{*}{ 6. Kekuatan } & 6. Kekuatan & $5-10 \mathrm{~kg}$ & $\mathrm{H}$ \\
\hline & 3a. Posisi badan & $44^{\circ}$ & $\mathrm{H}$ \\
\hline \multirow[t]{2}{*}{ 7. Getaran } & 7. Getaran & Tanpa alat bantu & $\mathrm{L}$ \\
\hline & 2a. Posisi badan & $21^{\circ}$ & $\mathrm{H}$ \\
\hline \multirow[t]{2}{*}{ 8.Kontak Stres } & 8. Pengaruh alat & Tanpa alat bantu & $\mathrm{H}$ \\
\hline & 2a. Posisi badan & $21^{\circ}$ & $\mathrm{H}$ \\
\hline \multirow[t]{2}{*}{ 9. Waktu Kerja } & 9. Waktu kerja & Melebihi 4 jam & $\mathrm{H}$ \\
\hline & 6. Kekuatan & $5-10 \mathrm{~kg}$ & $\mathrm{H}$ \\
\hline
\end{tabular}

Sumber: Pengolahan data

Pada Tabel 1 diketahui faktor fisik yang dimulai dari bahu memiliki postur $75^{\circ}$ dengan gerakan yang ringan tidak berkelanjutan atau berulang. Gerakan pergelangan tangan memiliki postur $21^{\circ}$ dengan gerakan memutar sehingga sangat berisiko cedera. Gerakan punggung memiliki gerakan ringan dan postur $44^{\circ}$ dengan posisi tersebut sangat berisiko cedera. Gerakan leher dengan gerakan pengulangan rendah dan postur $26^{\circ}$ dengan posisi tersebut memiliki risiko yang tinggi. Gerakan kaki memiliki posisi tegak lurus 
memiliki risiko rendah dan memiliki durasi kerja 4 jam yang risiko cedera yang tinggi. Kekuatan tumpu yang dibebankan sekitar $5 \mathrm{~kg}$ berisiko tinggi jika dilakukan berulang dengan posisi punggung $44^{\circ}$. Tidak ada getaran dari alat bantu akan tetapi posisi pergelangan $22^{\circ}$ berisiko tinggi akan cedera. Kontak stres saat melakukan pemasangan tidak menggunakan sarung tangan sehingga berisiko tinggi akan cedera jika dilakukan berulang. Dari pengelompokan perhitungan WERA sheet dilakukan perhitungan kembali dengan hasil skoring untuk mendapatkan skor akhir pada stasiun pemasangan fire brick di Tabel 2.

Tabel 2. Hasil skoring WERA stasiun pemasangan fire brick

\begin{tabular}{|c|c|c|c|c|c|c|c|c|c|c|c|c|c|c|c|}
\hline 1 & & $1 \mathrm{a}$. & Posi & Tubuh & 4 & 4a. Posis & tubs & & & & 7 & 7. G & tara & & \\
\hline$\Xi$ & $\begin{array}{l}\text { Level } \\
\text { Risiko }\end{array}$ & $\mathrm{L}$ & M & $\mathrm{H}$ & 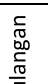 & $\begin{array}{l}\text { Level } \\
\text { Risiko }\end{array}$ & $\mathrm{L}$ & M & $\mathrm{H}$ & & & $\begin{array}{l}\text { Level } \\
\text { Risiko }\end{array}$ & $\mathrm{L}$ & $\mathrm{M}$ & $\mathrm{H}$ \\
\hline$\stackrel{50}{0}$ & $\mathrm{~L}$ & 2 & 3 & 4 & $\overline{\bar{m}}$ & $\mathrm{~L}$ & 2 & 3 & 4 & & 气 & $\mathrm{L}$ & 2 & 3 & 4 \\
\hline$\frac{\bar{\Xi}}{7}$ & M & 3 & & 5 & $\begin{array}{l}0 \\
0 \\
0\end{array}$ & M & 3 & 4 & 5 & & ثूّ & M & 3 & 4 & 5 \\
\hline 50 & $\mathrm{H}$ & 4 & 5 & 6 & & $\mathrm{H}$ & 4 & 5 & 6 & & तై & $\mathrm{H}$ & 4 & 5 & 6 \\
\hline 2 & & & & 4 & & Sk & & & 5 & & & & or & & 4 \\
\hline$\dot{\theta}$ & & & & & & & & & & & & & & & \\
\hline 2 & & $2 \mathrm{a}$. & osi & Tubuh & 5 & 5a. Posis & Tub & & & & 8 & 8. Kont & $\mathrm{kS}$ & res & \\
\hline$\underset{\pi}{\complement}$ & $\begin{array}{l}\text { Level } \\
\text { Risiko }\end{array}$ & $\mathrm{L}$ & $\mathrm{M}$ & $\mathrm{H}$ & $\pi$ & $\begin{array}{c}\text { Level } \\
\text { Risiko }\end{array}$ & $\mathrm{L}$ & M & $\mathrm{H}$ & & & $\begin{array}{l}\text { Level } \\
\text { Risiko }\end{array}$ & $\mathrm{L}$ & M & $\mathrm{H}$ \\
\hline$\frac{5}{\frac{5}{5}}$ & $\mathrm{~L}$ & 2 & 3 & 4 & $\underline{\bar{\Xi}}$ & L & 2 & 3 & 4 & & 总 & $\mathrm{L}$ & 2 & 3 & 4 \\
\hline 㐫 & M & 3 & 4 & 5 & 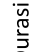 & M & 3 & 4 & 5 & & : & M & 3 & 4 & 5 \\
\hline & $\mathrm{H}$ & 4 & 5 & 6 & & $\mathrm{H}$ & 4 & 5 & 6 & & & $\mathrm{H}$ & 4 & 5 & 6 \\
\hline & & $\mathrm{Sk}$ & or & 5 & & Sk & & & 4 & & & & or & & 6 \\
\hline 3 & & 3a. & Posi & Tubuh & 6 & 6. Kek & uatar & & & & 9 & 9. Wakt & $\mathrm{d} K$ & rja & \\
\hline & & & & & & Level & & M & $\mathrm{H}$ & & & & $\mathrm{L}$ & M & $\mathrm{H}$ \\
\hline$\underset{\pi}{c}$ & Risiko & L & M & $\mathrm{H}$ & & Risiko & & & & & & Risiko & & & \\
\hline 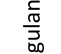 & $\mathrm{L}$ & 2 & 3 & 4 & 弄 & $\mathrm{L}$ & 2 & 3 & 4 & 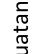 & & $\mathrm{L}$ & 2 & 3 & 4 \\
\hline $\begin{array}{l}\overline{0} \\
\dot{0} \\
\dot{m}\end{array}$ & M & 3 & 4 & 5 & m & M & 3 & 4 & 5 & 离 & & M & 3 & 4 & 5 \\
\hline & $\mathrm{H}$ & 4 & 5 & 6 & & $\mathrm{H}$ & 4 & 5 & 6 & & & $\mathrm{H}$ & 4 & 5 & 6 \\
\hline & & $\mathrm{Sk}$ & or & 4 & & Sk & & & 6 & & & & or & & 6 \\
\hline & & & & & & & & & & & & Final S & & 44 & \\
\hline
\end{tabular}

Sumber: Pengolahan data

Pada Tabel 2 merupakan hasil penilaian pada aktivitas stasiun kerja pemasangan pada posisi bahu dengan intensitas sedang dan $1 \mathrm{~b}$ memiliki gerakan pengulangan dengan intensitas sedang sehingga memperoleh skor penilaian 4. Pergelangan tangan memiliki intensitas tinggi dan $2 \mathrm{~b}$ memiliki gerakan pengulangan dengan intensitas sedang sehingga memperoleh skor penilaian 5. Punggung memiliki intensitas tinggi dan $3 \mathrm{~b}$ memiliki gerakan dengan intensitas rendah sehingga memperoleh skor 4 . Leher memiliki intensitas tinggi sehingga memperoleh skor penilaian 5. Kaki memiliki intensitas rendah dan durasi kerja dengan intensitas tinggi sehingga memperoleh skor 4. Kekuatan yang dibebankan memiliki intensitas tinggi sehingga memperoleh skor 6 . Tidak ada getaran dari alat bantu sehingga memperoleh skor 4. Kontak stres memiliki intensitas tinggi sehingga memperoleh skor penilaian 6. Durasi kerja memiliki intensitas tinggi dengan nilai 6 dijumlah dengan nilai hasil pada setiap posisi tubuh pada aktivitas stasiun kerja pemasangan didapatkan nilai akhir 44. Nilai 44 termasuk dalam kategori menengah sehingga diperlukan perbaikan postur dengan melakukan perubahan postur tubuh yang lebih baik. Pengelompokan evaluasi posisi kerja serta kalkulasi menggunakan metode WERA pada 3 posisi tubuh di beberapa stasiun kerja yang ada pada Tabel 3 . 


\begin{tabular}{lllllllllllll}
\multicolumn{10}{c}{ Tabel 3. Kalkulasi skoring WERA dan analisis postur kerja } \\
\hline No & Breakdown Kerja & $\mathbf{1}$ & $\mathbf{2}$ & $\mathbf{3}$ & $\mathbf{4}$ & $\mathbf{5}$ & $\mathbf{6}$ & $\mathbf{7}$ & $\mathbf{8}$ & $\mathbf{9}$ & Total & Level \\
\hline $\mathbf{1}$ & Pengambilan & 4 & 4 & 6 & 4 & 4 & 4 & 5 & 6 & 4 & 41 & Medium \\
\hline $\mathbf{2}$ & Pengangkatan & 4 & 5 & 5 & 4 & 5 & 4 & 3 & 5 & 4 & 39 & Medium \\
\hline $\mathbf{3}$ & Pemasangan & 4 & 5 & 4 & 5 & 4 & 6 & 4 & 6 & 6 & 44 & Medium \\
\hline
\end{tabular}

Hasil akhir perhitungan WERA Tabel 3 bahwa dari ketiga stasiun kerja yaitu proses pengambilan dengan total 41, proses pengangkatan dengan skor akhir 39, dan proses pemasangan dengan skor akhir 44 . Dari ketiga stasiun kerja yang paling berisiko yaitu proses pemasangan karena mendekati tingkatan level high yaitu 45. Sehingga membutuhkan perbaikan gerakan postur tubuh untuk mengurangi cedera pada operator yang bekerja pada PT. ABA.

\section{Penilaian Menggunakan Metode RULA}

Perhitungan skoring dari penilaian RULA sesuai worksheet di Gambar 3 di breakdown menjadi bagian A menghitung skor tubuh bagian lengan dan pergelangan tangan. Bagian B menghitung skor tubuh bagian leher, punggung, dan kaki. Lembaran Grand skor didapatkan dari hasil perhitungan antara skor $\mathrm{C}$ dan D. Hasil dari skoring RULA ditabulasikan Tabel 4.

Tabel 4. Skor RULA pemasangan grup A

\begin{tabular}{|c|c|c|c|c|c|c|c|c|c|}
\hline \multirow{4}{*}{$\begin{array}{l}\text { Lengan } \\
\text { Atas }\end{array}$} & \multirow{2}{*}{ Group A } & \multicolumn{8}{|c|}{ Wrist } \\
\hline & & \multirow{2}{*}{\multicolumn{2}{|c|}{$\begin{array}{c}1 \\
\text { Pergelangan } \\
\text { Tangan } \\
\end{array}$}} & \multirow{2}{*}{\multicolumn{3}{|c|}{$\begin{array}{c}2 \\
\text { Pergelangan } \\
\text { Tangan } \\
\end{array}$}} & \multirow{2}{*}{\multicolumn{2}{|c|}{$\begin{array}{c}3 \\
\text { Pergelangan } \\
\text { Tangan } \\
\end{array}$}} & \multirow{3}{*}{$\begin{array}{c}4 \\
\text { Pergelangan } \\
\text { Tangan } \\
\end{array}$} \\
\hline & \multirow{2}{*}{$\begin{array}{l}\text { Lengan } \\
\text { Bawah }\end{array}$} & & & & & & & & \\
\hline & & 1 & 2 & 1 & 2 & 1 & 2 & & \\
\hline \multirow{4}{*}{1} & 1 & 1 & 2 & 2 & 2 & 2 & 3 & 3 & 3 \\
\hline & 2 & 2 & 2 & 2 & 2 & 3 & 3 & 3 & 3 \\
\hline & 3 & 2 & 3 & 3 & 3 & 3 & 3 & 4 & 4 \\
\hline & 1 & 2 & 3 & 3 & 3 & 3 & 4 & 4 & 4 \\
\hline \multirow[t]{2}{*}{2} & 2 & 3 & 3 & 3 & 3 & 3 & 4 & 4 & 4 \\
\hline & 3 & 3 & 4 & 3 & 3 & 3 & 4 & 5 & 5 \\
\hline \multirow{3}{*}{3} & 1 & 3 & 3 & 4 & 4 & 4 & 4 & 5 & 5 \\
\hline & 2 & 3 & 4 & 4 & 4 & 4 & 4 & 5 & 5 \\
\hline & 3 & 4 & 4 & 3 & 4 & 4 & 4 & 5 & 5 \\
\hline \multirow{3}{*}{4} & 1 & 4 & 4 & 4 & 4 & 4 & 4 & 5 & 5 \\
\hline & 2 & 4 & 4 & 4 & 4 & 4 & 4 & 5 & 5 \\
\hline & 3 & 4 & 4 & 4 & 5 & 5 & 5 & 6 & 6 \\
\hline \multirow{3}{*}{5} & 1 & 5 & 5 & 5 & 5 & 5 & 6 & 6 & 7 \\
\hline & 2 & 5 & 6 & 6 & 6 & 7 & 7 & 7 & 8 \\
\hline & 3 & 6 & 6 & 6 & 7 & 7 & 7 & 7 & 8 \\
\hline \multirow{3}{*}{6} & 1 & 7 & 7 & 7 & 7 & 7 & 8 & 8 & 9 \\
\hline & 2 & 8 & 8 & 8 & 8 & 8 & 9 & 9 & 9 \\
\hline & 3 & 9 & 9 & 9 & 9 & 9 & 9 & 9 & 9 \\
\hline
\end{tabular}

Dari Tabel 4, bagian A didapatkan lengan atas dengan nilai 3 dari sudut $75^{\circ}$, lengan bagian bawah dengan nilai 2 dari sudut $66^{\circ}$, pergelangan tangan memperoleh nilai 2 , dan putaran pergelangan tangan karena berada di posisi tengah diperoleh nilai 1 . Hasil dari ke 4 nilai tersebut terdapat titik temu dengan nilai 4 pada worksheet A. Dari pengelompokan stasiun pemasangan grup B perhitungan bagian tubuh leher, punggung dan kaki akan diperoleh hasil akhir dengan Tabel 5.

Dari Tabel 5 diketahui bahwa bagian leher dengan nilai 3 dari sudut $26^{\circ}$, bagian punggung dengan nilai 3 dari sudut $44^{\circ}$, bagian kaki dengan nilai 1 karena beban tersebar merata dan terdapat ruang berganti posisi. Hasil skor dari ketiga bagian mendapatkan nilai 4 pada worksheet B. Pemberian nilai Grand Score RULA pada bagian pemasangan memiliki nilai posisi tubuh grup A dengan memperoleh nilai 3. Pemberian nilai posisi tubuh grup B mendapatkan nilai 2. Pada pembebanan kemudian ditambah skor 2 disebabkan beban 2-10 kg dan berulang. Serta menggunakan otot diberi skor 1 karena penggunaan postur berulang dalam 1 menit. Hasil pengelompokan nilai grand score pengambilan dapat diperoleh dari skor $\mathrm{C}=$ skor A + pembebanan + nilai aktivitas pemakaian otot, maka nilai $C$ yang diperoleh $4+2+1=7$. Sedangkan skor $D$ $=$ skor $\mathrm{B}+$ pembebanan + nilai penggunaan otot, maka nilai $\mathrm{D}$ yang diperoleh $4+2+1=7$, berikut hasil perhitungan Grand Score di Tabel 6. 
Tabel 5. Skor RULA pemasangan grup B

\begin{tabular}{|c|c|c|c|c|c|c|c|c|c|c|c|c|}
\hline \multirow{3}{*}{$\begin{array}{c}\text { Grup } \\
\text { B }\end{array}$} & \multicolumn{12}{|c|}{ Nilai postur tubuh } \\
\hline & \multicolumn{2}{|c|}{1} & \multicolumn{2}{|c|}{2} & \multicolumn{2}{|c|}{3} & \multicolumn{2}{|c|}{4} & \multicolumn{2}{|c|}{5} & \multicolumn{2}{|c|}{6} \\
\hline & \multicolumn{2}{|c|}{ Kaki } & \multicolumn{2}{|c|}{ Kaki } & \multicolumn{2}{|c|}{ Kaki } & \multicolumn{2}{|c|}{ Kaki } & \multicolumn{2}{|c|}{ Kaki } & \multicolumn{2}{|c|}{ Kaki } \\
\hline Leher & 1 & 2 & 1 & 2 & 1 & 2 & 1 & 2 & 1 & 2 & 1 & 2 \\
\hline 1 & 1 & 3 & 2 & 3 & 3 & 4 & 5 & 5 & 6 & 6 & 7 & 7 \\
\hline 2 & 2 & 3 & 2 & 3 & 4 & 5 & 5 & 5 & 6 & 7 & 7 & 7 \\
\hline 3 & 3 & 3 & 3 & 4 & 4 & 5 & 5 & 6 & 6 & 7 & 7 & 7 \\
\hline 4 & 5 & 5 & 5 & 6 & 6 & 7 & 7 & 7 & 7 & 7 & 8 & 8 \\
\hline 5 & 7 & 7 & 7 & 7 & 7 & 8 & 8 & 8 & 8 & 8 & 8 & 8 \\
\hline 6 & 8 & 8 & 8 & 8 & 8 & 8 & 8 & 9 & 9 & 9 & 9 & 9 \\
\hline
\end{tabular}

Tabel 6. Grand score RULA

\begin{tabular}{cccccccc}
\hline \multirow{2}{*}{ Skor C } & 1 & 2 & 3 & 4 & 5 & 6 & $7+$ \\
\hline 1 & 1 & 2 & 3 & 3 & 4 & 5 & 5 \\
2 & 2 & 2 & 3 & 4 & 4 & 5 & 5 \\
3 & 3 & 3 & 3 & 4 & 4 & 5 & 6 \\
4 & 3 & 3 & 3 & 4 & 5 & 6 & 6 \\
5 & 4 & 4 & 4 & 5 & 6 & 7 & 7 \\
6 & 4 & 4 & 5 & 6 & 6 & 7 & 7 \\
7 & 5 & 5 & 6 & 6 & 7 & 7 & 7 \\
$8+$ & 5 & 5 & 6 & 7 & 7 & 7 & 7 \\
\hline \multicolumn{7}{c}{ Sumber: Pengolahan data } \\
\end{tabular}

Berdasarkan nilai grand score pada hasil akhir proses pemasangan batu fire brick adalah 7 dikategorikan potensi risiko tinggi sehingga dibutuhkan segera perbaikan gerakan posisi kerja pada stasiun pemasangan fire brick. Hasil rekapitulasi perhitungan dari metode WERA dan RULA di Tabel 7.

Tabel 7. Rekapitulasi evaluasi tingkat risiko ergonomi WERA dan RULA

\begin{tabular}{cccccc}
\hline \multirow{2}{*}{ No. } & \multirow{2}{*}{$\begin{array}{c}\text { Stasiun } \\
\text { Kerja }\end{array}$} & Skor & Tingkat Risiko & Skor & Tingkat Risiko \\
\cline { 3 - 6 } $\mathbf{1}$ & Pengambilan & 41 & Medium & 7 & High \\
\hline $\mathbf{2}$ & Pengangkatan & 39 & Medium & 6 & Medium \\
\hline $\mathbf{3}$ & Pemasangan & 44 & Medium & 7 & High \\
\hline
\end{tabular}

Hasil evaluasi postur kerja di Tabel 7 dapat disimpulkan bahwa pada stasiun kerja pengangkatan fire brick memiliki intensitas risiko yang lebih rendah dengan memperoleh skor WERA 39 dan skor RULA 6 dengan intensitas risiko sedang. Pada stasiun kerja pengambilan memiliki skor WERA 41 dengan intensitas risiko sedang dan mendapatkan skor 7 pada RULA dengan intensitas risiko tinggi. Pada stasiun kerja pemasangan memiliki skor WERA 44 dengan intensitas risiko sedang dan mendapatkan skor 7 pada RULA dengan intensitas risiko tinggi.

\section{Kesimpulan}

Berdasarkan pembahasan dan analisis mengenai musculoskeletal disorder pada operator pemasangan fire brick dari hasil perhitungan metode WERA dan RULA dapat memberikan perbaikan untuk penurunan risiko musculoskeletal disorder. Kesimpulan pertama berdasarkan identifikasi pada postur tubuh pekerja pemasangan fire brick dengan menggunakan metode WERA dan RULA, diketahui bahwa hasil yang memiliki risiko kelelahan berlebihan pada bagian leher, bahu, dan punggung bawah.

Kesimpulan yang kedua berdasarkan postur kerja pemasangan fire brick dengan hasil analisis menggunakan metode WERA dan RULA dapat disimpulkan bahwa metode skor level risiko metode WERA memiliki nilai sebesar 44 dengan level medium dan diperlukan perubahan posisi postur tubuh. Sedangkan dari skor akhir dengan menggunakan metode RULA memiliki nilai 7 yang berarti berbahaya bagi pekerja agar segera dilakukan perbaikan postur tubuh dan pemeriksaan pada pekerjanya.

Hasil rekomendasi evaluasi postur kerja yaitu pekerja dalam melakukan aktivitas sebaiknya memperhatikan posisi tubuh yang baik dan benar, untuk meminimalisir tingkat cedera pada pekerja dan 
keluhan yang timbul setelah melakukan pekerjaan tersebut. Selain itu dapat dilakukan pelatihan pada pekerja yang akan melakukan pekerjaan yang ada pada perusahaan tersebut agar dapat bekerja secara maksimal dan tidak merugikan pekerja.

Kelemahan pada penelitian ini yaitu evaluasi risiko ergonomi hanya dilakukan pada satu pekerjaan yaitu aktivitas pemasangan fire brick. Kelemahan kedua yaitu pada penelitian ini tidak mempertimbangkan faktor lingkungan fisik ketika melakukan pekerjaan pada mesin kiln dan tidak mempertimbangkan faktor psikologis pekerjaan tersebut. Peluang penelitian selanjutnya yaitu dilakukan evaluasi risiko ergonomi pada aktivitas lain selain pekerjaan refractory sehingga implementasi ergonomi risk tidak hanya menggunakan metode RULA dan REBA. Penelitian berbasis human error SHERPA dan HEART, dan penelitian yang mempertimbangkan lingkungan fisik pekerjaan merupakan saran penelitian lanjutan guna mendapatkan studi kasus yang komprehenship pada bidang fokus risiko ergonomi.

\section{Referensi}

[1] D. S. Putro, "Strategi Perbaikan Implementasi Manajemen Keselamatan dan Kesehatan Kerja (K3) TPAS Wisata Edukasi Tulungagung Kabupaten Malang," J. Serambi Eng., vol. 4, no. 3, pp. $2017-$ 2023, 2021, doi: https://doi.org/10.32672/jse.v6i3.3050.

[2] A. Fiatno, R. Muhammad, N. D. Pratiwi, I. Mubaroq, dan A. Rahman, "Analisis Postur Tubuh Pekerja Mesin Pembelah Kayu Di Industri Mebel Supri Menggunakan Metode Rula," J. Tek. Ind. Terintegrasi (JUTIN), vol. 1, no. 2, p. 13 - 16, 2019.

[3] M. I. Hamdy, M. Nur, A. Mas'ari, dan F. E. Suheri, “Analisa Postur Kerja Manual Material Handling $(\mathrm{MMH})$ pada Karyawan Bagian Pembuatan Block Menggunakan Metode Rapid Upper Limb Assessment (RULA) (Studi Kasus: PT Asia Forestama Raya)," J. Hasil Penelitian dan Karya Ilmiah dalam Bidang Teknik Industri, vol. 5, no. 1, p. 62-65, 2019, doi: 10.24014/jti.v5i1.7432.

[4] A. Anwardi, N. Nofirza, dan H. Jasri, "Perancangan Alat Bantu Memanen Karet Ergonomis Guna Mengurangi Resiko Musculoskeletal Disorder Menggunakan Metode RULA dan EFD," J. Tek. Ind. J. Has. Penelit. dan Karya Ilm. dalam Bid. Tek. Ind.,, vol. 5, no. 2, p. 139, 2019, doi: 10.24014/jti.v5i2.9000.

[5] N. M. Dewantari, "Analisis postur Kerja Dengan Metode Rapid Upper Limb Assesment (RULA) Pada Operator Bar Bending Di PT.XYZ," J. Optimasi Tek. Ind., vol. 1, no. 2, p. 6, 2019, doi: 10.30998/joti.v1i2.4439.

[6] A. P. D. Fauza dan N. A. Mahbubah, "Analisis Postur Pekerja Pada Proses Produksi Tahu Berdasarkan Metode Rapid Entire Body Assessment Di CV Lahan Faedah," Teknologi, vol. 14, no. 1, p. 72-82, 2021, doi: https://doi.org/10.3415/jurtek.v14i1.3548.

[7] T. I. Oesman, E. Irawan dan P. Wisnubroto, "Analisis Postur Kerja dengan RULA Guna Penilaian Tingkat Risiko Upper Extremity Work-Related Musculoskeletal Disorders: Studi Kasus PT. Mandiri Jogja Internasional," J. Ergon. Indones. (The Indones. J. Ergon), vol. 5, no. 1, p. 39-46, 2019, doi: 10.24843/jei.2019.v05.i01.p06.

[8] A. D. Eka, N. A. Mahbubah, dan D. Andesta, "Analisis Postur Kerja Pada Pekerja Di Jalan Rel Dengan Pendekatan Metode Wera dan JSI," JUSTI (Jurnal Sist. dan Tek. Ind.,) vol. 1, no. 3, p. 434443, 2020, doi: http://dx.doi.org/10.30587/justicb.v1i3.2623.

[9] M. Imron, “Analisis Tingkat Ergonomi Postur Kerja Karyawan Di Laboratorium KCP PT. Steelindo Wahana Perkasa Dengan Metode Rapid Upper Limb Assessment (Rula), Rapid Entire Body Assessment (Reba) dan Ovako Working Posture Analisys (Owas),"JITMI (Jurnal Ilm. Tek. dan Manaj. Ind.) vol. 2, no. 2, p. 147-151, 2019, doi: 10.32493/jitmi.v2i2.y2019.p147-153.

[10] N. Aliafari, O. R. Pertiwi, M. T. Anugerah, dan A. D. Sari, "Analisis Eksposur Kerja pada Lini Produksi Batik Menggunakan Metode Workplace Ergonomic Risk Assessment," in Seminar dan Konferensi Nasional IDEC, 2018, no ISSN: 2579-6429.

[11] S. Siswanto, P. Pusporini, dan E. Ismiyah, "Analisis Postur Kerja Operator Sablon Karung Dengan Metode Rula Dan Wera,” JUSTI (Jurnal Sist. dan Tek. Ind), vol. 1, no. 4, p. 591-608, 2020.

[12] M. W. Andry Septianto, "Analisa Perbaikan Postur Kerja Pekerja Dalam Ilmu Ergonomi Menggunakan Metode Workplace Ergonomics Risk Assessment (WERA) dan Standard Nordic Questionnaire (SNQ)," Ergon. dan K3, vol. 6, no. 1, p. 35-42, 2021.

[13] M. Siska dan S. A. Angrayni, "Analisis Postur Kerja Manual Material Handling pada Aktivitas Pemindahan Pallet Menggunakan Rappid Upper Limb Activity (RULA) di PT. Alam Permata Riau," 
J. Sains, Teknol. dan Ind., vol. 15, no. 2, p. 77-86, 2018, [Online]. Available: http://ejournal.uinsuska.ac.id/index.php/sitekin/article/view/4440.

[14] M. N. asrul, A. Rahman, M. R. eb, A. Rani and a. J. M. o. Rohani, "WERA: an observational tool develop to investigate the physical risk factor associated with WMSDs," J Hum, Ergol, vol. 40, no. 1-2, pp. 19-36, 2011, doi: 10.11183/jhe.40.19..

[15] L. a. C. E. M. McAtamney, RULA: A Survey Based Method for The Investigation of Work Related Upper Limb Disorders., 24 (2) ed., United State: Applied Ergonomics, 1993, pp. 91-92.

[16] B. Widanarko, W. Kusmasari, Y. Yassierli and a. H. Iridiastadi, "Instrumen Survei Gangguan OtotRangka," 2016. [Online]. Available: http://www.pei.or.id/images/dokumen/instrumen-surveikeluhan.pdf. 